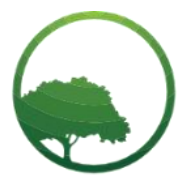

Business \& Social Science IJRBS

\section{Research in Business \& Social Science}

IJRBS VOL 10 NO 4 ISSN: 2147-4478

Available online at www.ssbfnet.com

Journal homepage: https://www.ssbfnet.com/ojs/index.php/ijrbs

\title{
Determinants of sales revenue in innovation diffusion effects of Taiwan sports lottery during the FIFA World Cup 2018
}

\author{
(DD) Day-Yang Liu ${ }^{(a)}$ (iD) Wen-Chun Tsai ${ }^{(b)^{*}}$ (D) Pei-Leen Liu ${ }^{(c)}$ (D) Chung-Yi Fang ${ }^{(d)}$ \\ ${ }^{(a, b)}$ Graduate Institute of Finance, National Taiwan University of Science and Technology, Taipei, Taiwan

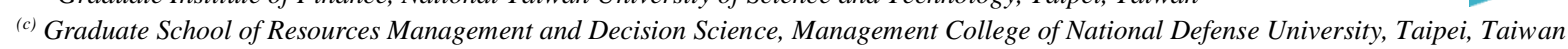 \\ ${ }^{(d)}$ Department of Financial Management, Management College of National Defense University, Taipei, Taiwan
}

\author{
ARTICLE INFO \\ Article history: \\ Received 13 May 2021 \\ Received in rev. form 29 May 2021 \\ Accepted 30 May 2021 \\ Keywords: \\ System Dynamics, Innovation \\ Diffusion, Sports Lottery \\ JEL Classification: \\ C69, G39, L25, M00
}

\begin{abstract}
A B S T R A C T
This article analyzes the factors affecting the sales revenue of sports lottery from the perspective of innovative diffusion theory by system dynamics analysis. With the quantification and simulation of system dynamics, the sales revenue of sports lottery is affected is found. With the daily sales amount during the FIFA World Cup 2018 as samples, six variables (reach frequency, adoption rate, betting among per person per day, advertisement expenditure, advertisement successful rate, and potential bettor increase rate) are used to find out the key factors. According to the simulation result of this study, it indicates that all the variables exert positive influence on the sales revenue. The magnitude of influence on sales, from large to small, they are betting among per person per day, reach frequency and adoption rate in word-to-mouth, potential bettors increase rate, advertisement expenditure and advertisement successful rate in the advertisement effects. During the FIFA World Cup 2018, advertising effects initiated the diffusion of sports lottery. Compared to the advertising effects, wordto-mouth effects were bigger. In the same situation and with same resources, Taiwan Sports Lottery, the operator could change the betting among per person per day and change the word-to-mouth advertising with priority. When major matches take place in the future, Taiwan Sports Lottery is suggested to judge if it maintains an optimistic attitude for future growth, it shall begin to promote advertising effects. When more people learn more about the sports lottery, with the diffusion of wordto-mouth advertising, the effects will be most significant.
\end{abstract}

(C) 2021 by the authors. Licensee SSBFNET, Istanbul, Turkey. This article is an open access article distributed under the terms and conditions of the Creative Commons Attribution (CC BY) license (http://creativecommons.org/licenses/by/4.0/).

\section{Introduction}

The emergence of the lottery industry and entertainment, and the promotion of high technology makes lottery easier to access. It is a rather common scenario for young generations to buy sports lottery (Jenkinson et al., 2019). The lottery industry grows around the world. In the past decades, the growth of sports lottery has been the fastest (Herskowitz, 2016). According to La Fleur's World Lottery Almanac, in 2019 the global sales of sports lottery was US\$ 108,752 million(La Fleur, 2019). The sales of sports lottery in Taiwan was ranked 6th in the world with US\$ 1,543 million. FIFA World Cup is a major and influential global match that takes place every four year. The sponsoring of FIFA brings the sponsoring country high economic benefits in tourism, broadcasting, advertisement, and stock market, all of which will be influenced by the FIFA (Cornelissen, 2010, Kaplanski and Levy, 2010, Lee and Taylor, 2005, Szymanski, 2002). When the FIFA World Cup took place, the sales revenue sports lottery in Taiwan was US\$ 28 million in 2010 ; US\$ 9 million in 2014; and US\$ 25 million in 2018. From 2014 to 2018, the sales revenue of sports lottery increased 194\%. In 2018, Taiwan Sports Lottery accumulated the sales of US\$ 2.5 billion during FIFA World Cup. During the champion race, it scored the sales of US\$ 30 million and contributed US\$ 25 million to the Sports Development Fund with a single international contest. In a month's time, it gathered people's power to create multiple records in the history of sports lottery. It is mainly because starting from the first group match, it provided single-bet, live-bet, and multiple-bet to attract consumers. In addition, the strong promotion

* Corresponding author. ORCID ID: 0000-0002-9435-658X

(C) 2021 by the authors. Hosting by SSBFNET. Peer review under responsibility of Center for Strategic Studies in Business and Finance. https://doi.org/10.20525/ijrbs.v10i4.1198 
campaign launched by Chunghwa Telecom was highly effective. The lively reports and frequent news broadcasted through media provoked consumers' interest in winning big bucks with small money. All these were contributing factors to the craze of sport lottery.

The issuing of sports lottery in Taiwan is outsourced to private company. Retailers increased from 50 in 2018 to 1,550 in 2019. Among them, about $63 \%$ of the sports lottery retailers operated by professionals. During the FIFA World Cup, they operated 24 hours a day, providing round the clock service to cope with the time lag - the matches started nearly at midnight in Taiwan. During the weekends in the middle of the night the sales occupied more than $60 \%$. Regarding the revenue and expenditure structure, $78 \%$ of the sales was the prize money; $10 \%$, government revenue; and $12 \%$ operational management expenditure. In recent years, it continues to grow, creating high sales. The virtual channel was put online on April 1, 2014. The growth of virtual and actual channels grew together. The ratio of online sales keeps growing year by year. In 2014, the total sales of actual and online channels were US\$ 860 million, in which sales through virtual channels occupied 7.5\%. In 2015, the total sales revenue was US\$1,010 million, in which sales revenue through virtual channels occupied $13.5 \%$. In 2016, the total sales revenue was US\$ 1,110 million, in which sales revenue through virtual channels occupied $16.4 \%$. In 2017 , the total sales revenue was US $\$ 1,180$ million, in which sales revenue through virtual channels occupied $18.4 \%$. In 2018 , the total sales revenue was US\$ 1,560 million, in which sales revenue through virtual channels occupied $21.3 \%$ at US\$ 330 million.

Diffusion is a process, through which, the communication among members in the system will be innovated in a certain period (Rogers, 2010). The diffusion model is an analysis of the diffusion process conducted with logical and mathematical functions (Rogers, 2010). Most mathematicians study it with logical and mathematical functions (Mahajan, 2010, Mahajan and Peterson, 1979, Blackman Jr, 1974). Most of the models are binomial distribution functions, and the result is presented in sigmoid curves. The limitation of binomial distribution functions is that it uses a fixed and potential number of people. To be closer to actual practice, case analysis can explain the condition better than the classic model. Therefore, simulating with system dynamics, the researcher can not only assume the parameter but also analyze different situations, getting closer to actual practice (Sharif and Ramanathan, 1984).

Innovation diffusion theory explains the speed and details of the communication of a new idea. FIFA World Cup is a non-normal and new sports lottery activity that happened in a period. It will exert a bigger influence on potential bettors (Uzochukwu, 2021). The match is a sports activity that is held every four years. Compared with other contests that are held frequently, the FIFA world cup is a comparatively new contest that is held for a month. The brevity of the duration attracts attention from more people. Influenced by advertising and word-to-mouth advertisement, it affects the acceptance of potential consumers and the popularity of betting. It promotes the sports lottery behavior among potential consumers, regarded as the diffusion of the product.

There are many variables affecting the features of the sports lottery's sales revenue. They are also inter-dependent. The study of innovation diffusion theory mainly uses logical and mathematical functions to propose basic diffusion models to predict and verify sales (Bass, 1969). It then derives many affecting variables further alternating the original model (Mahajan and Peterson, 1979, Robinson and Lakhani, 1975). Now, examining the local and international studies of the sales revenue of sports lottery, very few of them approached the issues of sports lottery sales revenue and innovation diffusion theory from the perspective of the total system. Therefore, the study analyzes and simulates FIFA World Cup 2018 with system dynamics, with the consideration of the aspects of advertising, word-to-mouth advertising, finance issues, and innovative diffusion models. The mutual influence of the variables will be discussed. Through domain experts and literature collection, the situation of policies will be analyzed. The results of this study will be helpful in the prediction of sports lottery sales revenue and complete the deficiency in literature. Suggestions will also be given to the making of the sales strategy of sports lottery sales revenue.

\section{Literature Review}

Employing system dynamics as a research method, models related to sports lottery will be constructed. Literature and studies below will be consulted in the discussion. First, it discusses the literature related to innovation diffusion theory and sports lottery. Then, system dynamics will be discussed.

\section{Diffusion of Innovation}

Diffusion of Innovation Theory is proposed by an American scholar Everett M Rogers, who believes innovation is a new concept, time, and thing adopted by people or organizations. Diffusion theory is mainly used to predict the adoption and popularity of a product by consumers in the market and the possible sales conditions in different periods. Then, the adoption and popularity of a product by consumers in the market will be predicted. This situation is regarded as the diffusion of a product (Rogers, 1961).

The users of innovations fall into five stages. The feature of related models is represented in an S-curve, the accumulated adopters' curve (Rogers and Williams, 1983). Adopters of innovation include innovators, early adopters, early majority, late majority, and laggards. Innovators occupy $2.5 \%$ of the market. Their features are brave pioneers that promote innovation consciously. In the promotion process, innovators take important responsibilities (Rogers, 1963). Early adopters occupy 13.5\% of the market. They are respected people in society, as well as leaders of public opinion. Their features are taking pleasure in leading the fashion and willing to try new things. But their behaviors are rather careful. Early majority occupies $34 \%$ of the market. They are a group of people with independent thinking, and their behaviors are rather careful. They are more willing to change when compared with ordinary people. Late majority occupies $34 \%$ of the market. They are a group of people suspicious of new products. They will adopt and use new 
products after the public in the society accept innovative things. Laggards occupy $16 \%$ of the market. They are a group of the most conservative people. They prefer following norms and traditions. They are picky towards innovative things. They will accept new things passively when they have become the major trend.

Recent studies emphasize the playing of the roles in analysis and strategy making (Mahajan et al., 2000). Consumers' participation rate has become more and more important in the market, creating values in the market. They play positive roles in the creation and competition of values (Prahalad and Ramaswamy, 2000). Also, enhancing the information of innovations and governance can improve the institutional performance (Mbore et al., 2019).

\section{Sports Lottery}

Mwadime (2017) It is believed that the accessibility of mobile payment exerts tremendous influence on obtaining sports lottery. In addition, social media is the most important information source, and the reference of decision making regarding whether new customers decide to buy sports lottery or not. In National Football League (NFL) - Super Bowl, advertisements attract the attention of TV viewers. From the perspective of the Hollywood Film Industry, the effects of advertisements in the Super Bowl contribute to the increase twice the box office takings of American movies (Yelkur et al., 2004). There are about 100 million viewers of the Super Bowl every year. It is the best time to achieve maximum advertisement effects. At the same time, it is also the period that advertisement cost to be the highest, more than $\$ 10$ million, which only large companies have the ability to afford the advertisement cost, such as Coca Cola, Budweiser, Nike, and others. According to surveys, in Australia, consumers that bet regularly watch advertisements of sports lottery every day (Hing et al., 2019). The types of advertisements most frequently and directly watched are email, text message, and phone calls from lottery companies. Compliance (2013) explained that sports lottery advertisements are broadcasted and promoted through TV broadcast, radio broadcast, websites, celebrities' endorsement, directly through emails, text messages, and more. Hing et al. (2014) explains that sports lottery companies mainly promote sales through sports lottery app or live sports lottery betting. Live matches broadcasts, cell phones or emails are used to attract bettors' betting.

\section{System Dynamics}

System dynamics was proposed by Jay W. Forrester, a professor of MIT, in 1956. Compared with traditional models, the merits of system dynamics include feedback effect that allows the construction to be closer to real situations and decision makers to understand the interrelationships of the models easily (Sterman, 1994). The complicated system and the feedback and delay of information behind the model can be represented with system dynamics (Sterman, 2000). System dynamics is always used to the overall behaviors of a complicated system in the course of time. Innovation diffusions are also used in system dynamics for the study of a new product from its launching into mature through simulation. It allows the decision maker to decide the product's price, promotion expenditure, and more in every season (Paich and Sterman, 1993). Milling (1996) developing a modularly composed model with system dynamics, it is employed to explain the relations between the changes in the product life cycle, the manufacturer's strategies, and market performance to understand the impacts of different pricing strategy, capacity expansion, and others on results of performance. In the past, system dynamics was used to analyzed product diffusion with the model proposed by Bass as a foundation(Bass, 1969). With the Bass model as a foundation, the adopters are categorized into two groups: expected impact, such as promotion advertising and adopters affected by word-to-mouth(Yeon et al., 2006). In the improved Bass model, the variable of price is added to predict market sales (Robinson and Lakhani, 1975) or the study of the impact of household growth rate on market potential (Mahajan and Peterson, 1979). The historical data of added variables can hardly be obtained. Most of them have the demerit of insufficient explanatory power. Therefore, this study uses system dynamics to examine the adoption and diffusion of sports lottery of FIFA World Cup from the perspective of time and the cause and effect among variables. According to the cycle, and the observations of the abovementioned literature and trends, FIFA World Cup is a match that is not held that often. Therefore, innovation diffusion theory can be used, integrating the perspective of system dynamics, to study the impacts of individuals and the society after adoption.

\section{Research and Methodology}

The modeling process is a systemic thinking and concept through the interviews of field experts and literature collections, applied to develop the system dynamics model of the sales of Taiwan's sports lottery. This project regards Taiwan Sports Lottery as the object of study. As Taiwan Sports Lottery is operated by ADATA TECHNOLOGY CO., LTD., the daily sales amount of FIFA World Cup 2018 is searched from the sports lottery sales amount and disposition of net profit of ADATA TECHNOLOGY CO., LTD., and the financial statements of Taiwan Sports Lottery. The sorting out of related financial statements, literature collections, and interviews of field experts are used as research methods (Forrester, 2007, Senge and Forrester, 1980) to find out the key factors that affected the daily amount of sales revenue of sports lottery of FIFA world cup 2018 as the foundation of constructing the qualitative model.

Furthermore, Vensim PLE 8.0.7 was used to construct the system dynamics figure of the Taiwan Sports Lottery. To promote the validity of the model, field experts, including the product manager of Taiwan Sports Lottery, director of the research center for the study of lottery and commercial gaming, and financial scholars, were interviewed with triangulation (Denzin, 2017, Denzin, 1970). Experts were invited to review and discuss the appropriateness of the variables in the qualitative model and to discuss the parameters of the quantitative model. 


\section{The Construction of System Dynamics Model}

System dynamics is used to explain the study FIFA World Cup with the integration of system dynamics and the diffusion of innovation theory. In Figure 1, it is the innovation diffusion model of the system dynamics model of Taiwan Sports Lottery's sales revenue system. It is indicated with two base quantities: potential bettor and bettor. When the increased rate of potential bettors increases, there will be more potential bettors. More bettors will also increase. On the contrary, when the increase rate of potential bettors decreases, and the number of potential bettors will also decrease. The number of bettors will also decrease.

The rate quantity of the potential bettor and bettor, adoption rate, will initiate the entire model with the advertisement effects. Then, with the impacts of word-to-mouth on bettors, the adoption opportunity of bettors will be enhanced. The better the word-to-mouth increase, the more the intentions in sharing with potential bettors. More potential bettors will become bettors. Part of the bettors will bet again affected by the word-to-mouth. When the match ends, they leave the betting market.

The sales revenue of a sports lottery company is affected by the bettors and the daily betting amount per person. The more bettors increase, the higher the amount of accumulated sales revenue. The higher the betting amount person, the higher the amount of accumulated sales revenue. On the contrary, the lesser the bettors decrease, the lesser the accumulated amount of sales revenue. The lesser the betting amount person, the lesser the amount of accumulated sales revenue.

This research employs the stock and flow diagram constructed by Vensim to create the quantitative model, such as Figure 1 the sales revenue system dynamics model of Taiwan Sports Lottery. Furthermore, according to actual data (mainly including the earning announcement of sports lottery declared by Sports Administration, Ministry of Education, financial statements of Taiwan Sports Lottery, and more) and scholars and experts (product manager of Taiwan Sports Lottery, director of the research center for the study of lottery and commercial gaming, financial scholars, and more) parameters of related variables are set to explain the Taiwan Sports Lottery's finance conditions and the operation of innovation diffusion.

The following four sub-systems composed of the main system dynamics system for the study. They are as follows:

(1) Quantification of innovation diffusion sub-system (quantification of human flow sub-system)

Figure 1 In the innovation and diffusion sub-system, according to Bass, the dynamics of bettors' human flow are found. The major manner of flow is formed by two stocks - potential bettors and bettors, and three rates - increase rate of potential bettors, adoption rate, and bettor exit rate. The potential increase rate is the membership number per day in FIFA World Cup 2018 divided by $21.3 \%$ to derive the potential bettor increase rate. It is used as a parameter setting. 




Figure 1: The Sales Revenue System Dynamics Model of Taiwan Sports Lottery 
Through advertising campaigns, for example, to offer prizes to attract young people and appeal to the convenience of betting online, it could capture the topic of FIFA. If extra advertisements and campaigns were promoted to attract more members and provide round the clock service on weekends, it could affect the adoption rate and initiate the sub-system of word-to-mouth.

(2) Quantification of advertising effects sub-system

Advertisement expenditure was a one-off payment. The advertisements of FIFA World Cup 2018 included magazines, newspapers, television, internet, and outdoor TV walls. According to the financial statements of Taiwan Sports Lottery, the total advertisement expenditure in 2018 was US\$ 0.71 million. It is used as a parameter setting.

(3) Quantification of word-to-mouth sub-system

The word-to-mouth effects sub-system explains potential bettors exert positive (or negative) influence on the adoption of a sports lottery commodity and its innovative online betting service. When the more the bettors, each of the bettors obtains higher value. In economics or business, this commodity has a positive network externality. It is also called the bandwagon effect. When the number of bettors decreases the value of each of the bettors will be lower. In economics or business, this commodity has a negative network externality. It is also called as snob effect. The reach frequency of each of the bettors, the adoption rate after betting, and the ratio of bettors to potential bettors will affect the word-to-mouth effects. According to the interview of the general manager and director of the betting center for the study of lottery and commercial gaming, during the FIFA World Cup 2018, the reach frequency of each bettor was 10 ; the adoption rate was 0.35 . They are used as parameter settings.

(4) Financial effects and the quantification of sub-system

The financial effects sub-system explains the accumulated sales amount of betting quantity of sports lottery per person per day. According to the interviews of field experts: the general manager and director of the betting center for the study of lottery and commercial gaming, during the FIFA World Cup 2018, the average betting amount per person per day was US\$148. It is used as a parameter setting.

\section{Simulation Validation and Analysis}

\section{Model validation}

In the model construction process in this research, according to the actual situation and secondary materials (including earning announcement of sports lottery announced by Sports Administration, Ministry of Education, financial statements of Taiwan Sports Lottery, and more) and the discussion of scholars and experts (the product manager of Taiwan Sports Lottery and director of the research center for the study of lottery and commercial gaming), Vensim PLE, system dynamics computer simulation software, the model's structure was developed. The rationale of the computer language was checked with the built-in mode. Comparing the simulated results with the actual situations, historical behavior trends validation was conducted. From June 14 to July 15 , during the FIFA World Cup 2018, the daily accumulated sales amount showed to be growing, as shown in Figure 2. The sales amount of the simulated trends and actual conditions are similar. According to Senge and Forrester (1980), the method of model validation was conducted. With reference Lewis (1982) to the evaluation standard yielded, Mean Absolute Percentage Error (MAPE) was used to conduct relative performance with simulated value and actual value. As MAPE was relative values, it would not be affected by the unit quantity of simulated values and actual values. Therefore, it was able to derive the difference between simulated value and actual value from an objective perspective. The related formula is as follow:

$$
\text { MAPE }=\left\{\frac{1}{n} \sum_{t=1}^{n}\left|\frac{R_{t}-S_{t}}{R_{t}}\right|\right\} \times 100 \%
$$

$n$ is the simulated period, $R_{t}$ is the actual values of $t$ period. $S_{t}$ is the simulated value of $t$ period. Lewis (1982) proposed Mean Absolute Percentage Error in four levels. It explains the accuracy of the model as Table 1. Taking the variable of trend difference validation percentage as an example, first, the absolute value is derived. Then, divide it with 27 periods, mean variable absolute error. For example, Source: Author

Table 2, the daily sales amount error is $6 \%$. To promote the accuracy, it shows that there is a certain degree of accuracy in the system behavior. In sum, the results indicate the structure model constructed by this research is valid to a certain degree.

Table 1: Mean Absolute Percentage Error Levels

\begin{tabular}{lcl}
\hline MAPE value & & Accuracy of prediction \\
\hline & $<\mathbf{1 0} \%$ & Highly accurate \\
\hline $\mathbf{1 0} \%-\mathbf{2 0} \%$ & Satisfactory \\
\hline $\mathbf{5 0} \%$ & & Reasonable \\
\hline
\end{tabular}


Source: Author

Table 2: Accuracy of Trend Validation Variable Simulation

\begin{tabular}{lll}
\hline Variable validation & MAPE value & Accuracy \\
\hline Daily accumulated sales amount & $6 \%$ & Highly accurate
\end{tabular}

Source: Author

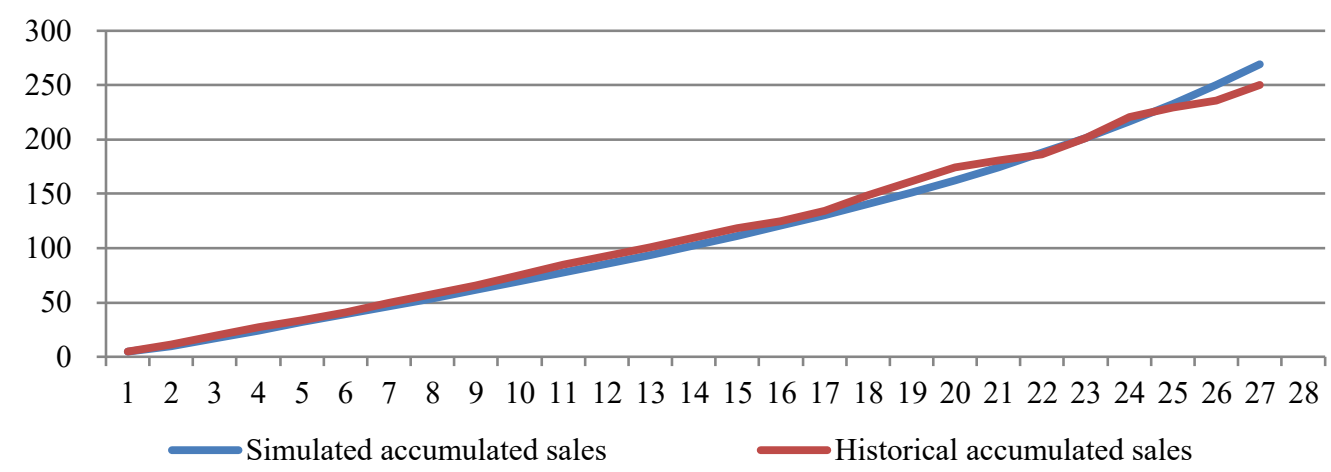

Figure 2: The trend of daily accumulated daily sales in FIFA World Cup (Unit: Million US\$ / Day)

Note: The exchange rate is 28 New Taiwan dollars for 1 U.S. dollar.

\section{Simulation Analysis}

Inspecting with the validation above, regarding the financial and innovation diffusion model constructed in this research, the simulated accumulated sales amount in congruent with the historic accumulated sales during the FIFA. This research used the number of days as the cycle of simulation to simulate the duration from November 21, 2022 (Cycle 0) to December 18, 2022 (Cycle 27), which totaled 27 cycles. Situation analysis of parameter settings was used, supposed in different situations, in three different conditions: design optimistic, standard, and conservative is made to observe the simulation changes of "the accumulated sales amount of sports lottery." The impacts of the variables on the operation of the Taiwan Sports Lottery were studied. Different from the static analysis conducted in the past, dynamic analysis was used to integrate the successful factors successful sales in online practice, such as "the popularization of mobile network," "support of sports lottery retailers," "use of social media," "promotion conducts of sales advertisement," "24-hour operation and services" with the system dynamics into the model of this research. The situation changes are as follows in Table 3:

Table 3: Simulation setting

\begin{tabular}{llll}
\hline Situation & Optimistic & Standard & Conservative \\
Simulation & 13 & $\begin{array}{l}10 \\
\text { (Maintain original setting) }\end{array}$ & 7 \\
\hline Reach frequency & 0.455 & $\begin{array}{l}0.35 \\
\text { (Maintain original setting) }\end{array}$ & 0.245 \\
\hline Adoption rate & 192 & $\begin{array}{l}148 \\
\text { (Maintain original setting) }\end{array}$ & 0.5 million \\
\hline Betting among per person per day & 0.92 million & $\begin{array}{l}0.71 \text { million } \\
\text { (Maintain original setting) }\end{array}$ & 0.0007 \\
\hline Advertisement expenditure & 0.0013 & $\begin{array}{l}0.001 \\
\text { (Maintain original setting) }\end{array}$ & $\begin{array}{l}1 \text { time } \\
\text { (Maintain original setting) }\end{array}$ \\
\hline Advertisement successful rate & 1.3 times & & 0.7 time \\
\hline Potential bettors increase rate & & & \\
\hline
\end{tabular}

Source: Author 
Note: The exchange rate is 28 New Taiwan dollars for 1 U.S. dollar.

Three situations are supposed in the research, as shown in Table 3 optimistic, standard, and conservative to conduct simulation analysis. In standard conditions, the variable is the reference point. The variable in the situation of optimism, supposed to be in standard condition, will increase by $30 \%$. In the situation of conservative, supposed to be in standard condition, it will decrease by $30 \%$. Integrated analysis are as follows:

\section{Simulation 1: The change of reach frequency of the population of betting in sports lottery}

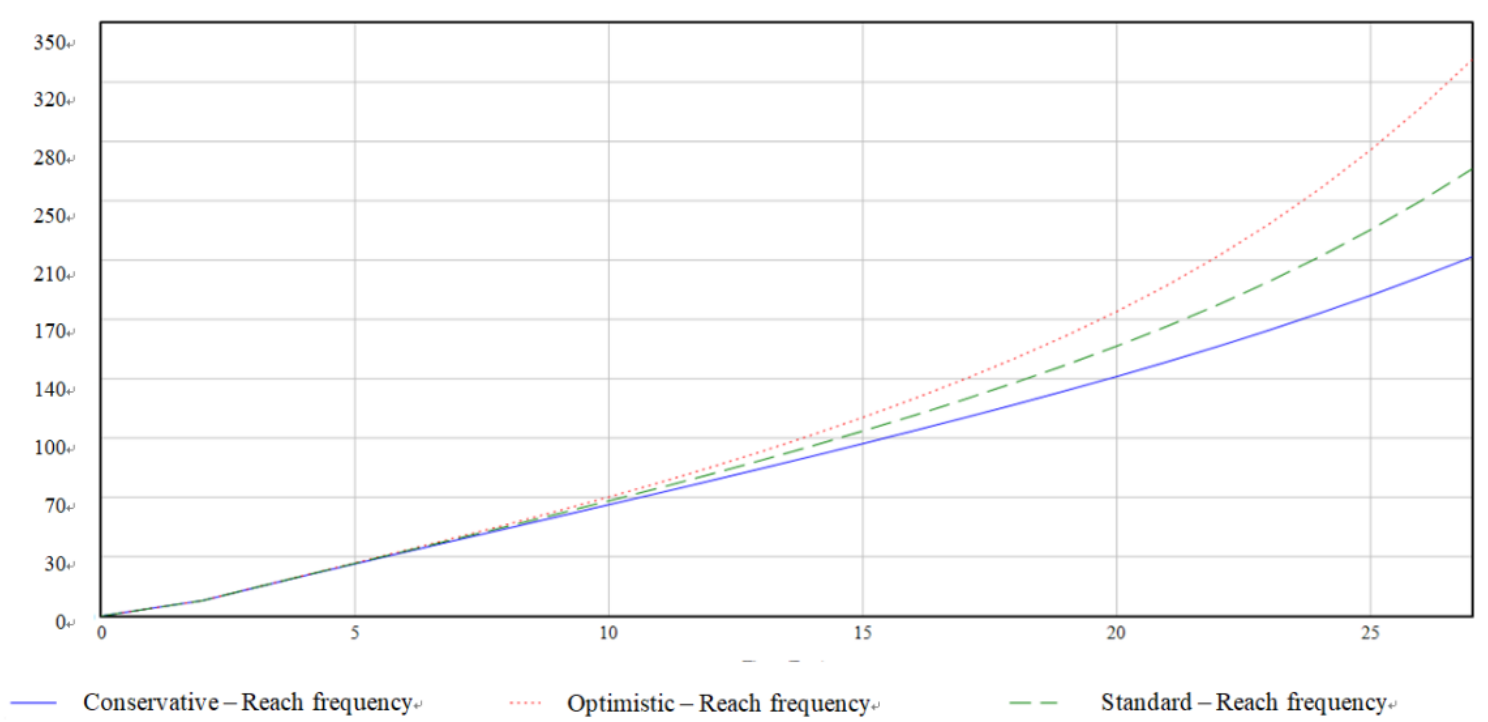

Figure : Regarding Simulation 1, the analysis of the simulated results of daily sales amount of sports lottery (Unit: Million US\$ / Day); Note: The exchange rate is 28 New Taiwan dollars for 1 U.S. dollar.

As shown in Figure 3 in the situations of optimistic, standard, and conservative, the trend of the growth of the accumulated sales amount of sports lottery is simulated. In the optimistic situation, up to the 9th day, the accumulated sales amount is about US\$ 60 million. On the 18th day, it is about US\$150 million. When accumulated to the 27 th day, it is about US\$ 0.32 billion. In the standard situation, up to the 9 th day, the accumulated sales amount is about US $\$ 0.06$ billion. On the 18th day, it is about US\$ 0.14 billion. When it is accumulated to the 27 th day, it is about US\$ 0.25 billion. In the conservative situation, up to the 9 th day, the accumulated sales amount is about US $\$ 0.06$ billion. On the 18 th day, it is about US $\$ 0.13$ billion. When it accumulated to the 27 th day, it is about US\$ 0.21 billion. The parameter regarding the population reach frequency change showed to have difference in accumulated sales amount. It indicates the change of population of reach frequency is sensitive towards the accumulated sales amount.

By changing the "reach frequency" with standard situation as the criteria, in the optimistic situation, the accumulated sales amount increases about $24 \%$ when compared with the standard situation. With the standard situation as the criteria, in conservative situation, the accumulated sales amount decreases about $20 \%$ when compared with the standard situation.

Simulation 2: Adoption rate change regarding the bettor population in sports lottery 


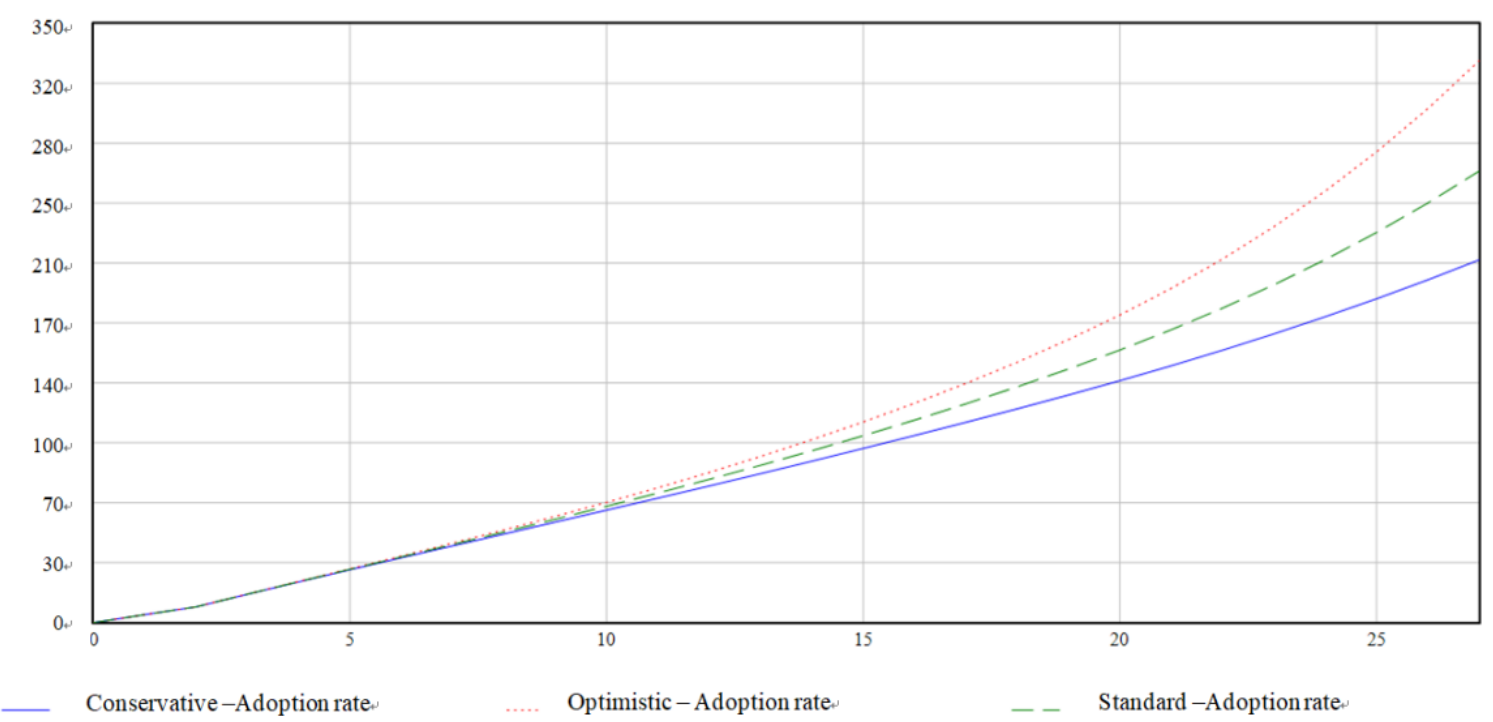

Figure 4: Regarding Simulation 2, the analysis of the simulated results of daily sales amount of sports lottery (Unit: Million US\$ / Day); Note: The exchange rate is 28 New Taiwan dollars for 1 U.S. dollar.

As shown in Figure 4 the changing of adoption rate in the bettor population, it shows to have growth in the accumulated sales amount of sports lottery. In the optimistic situation, up to the 9th day, the accumulated sales amount is about US\$0.06billion. On the 18th day, it is about US\$ 0.15 billion. When it is accumulated to the 27 th day, it is about US\$ 0.32 billion. In the standard situation, up to the 9th day, the accumulated sales amount is about US\$ 0.06 billion. On the 18th day, it is about US\$ 0.14 billion. When it is accumulated to the 27 th day, it is about US $\$ 0.25$ billion. In the conservative situation, up to the 9th day, the accumulated sales amount was about US\$ 0.06 billion. On the 18th day, it is about US\$ 0.13 billion. When it is accumulated to the 27 th day, it is about US\$ 0.21 billion. The parameter regarding the population of adoption rate change shows that it has difference in accumulated sales amount. It indicates the change of population of adoption rate is sensitive towards the accumulated sales amount.

By changing the "adoption rate" with standard situation as the criteria, in the optimistic situation, the accumulated sales amount increases about $24 \%$ when compared with the standard situation. With the standard situation as the criteria, in conservative situation, the accumulated sales amount decreases about $20 \%$ when compared with the standard situation.

\section{Simulation 3: Change of betting among per person per day}

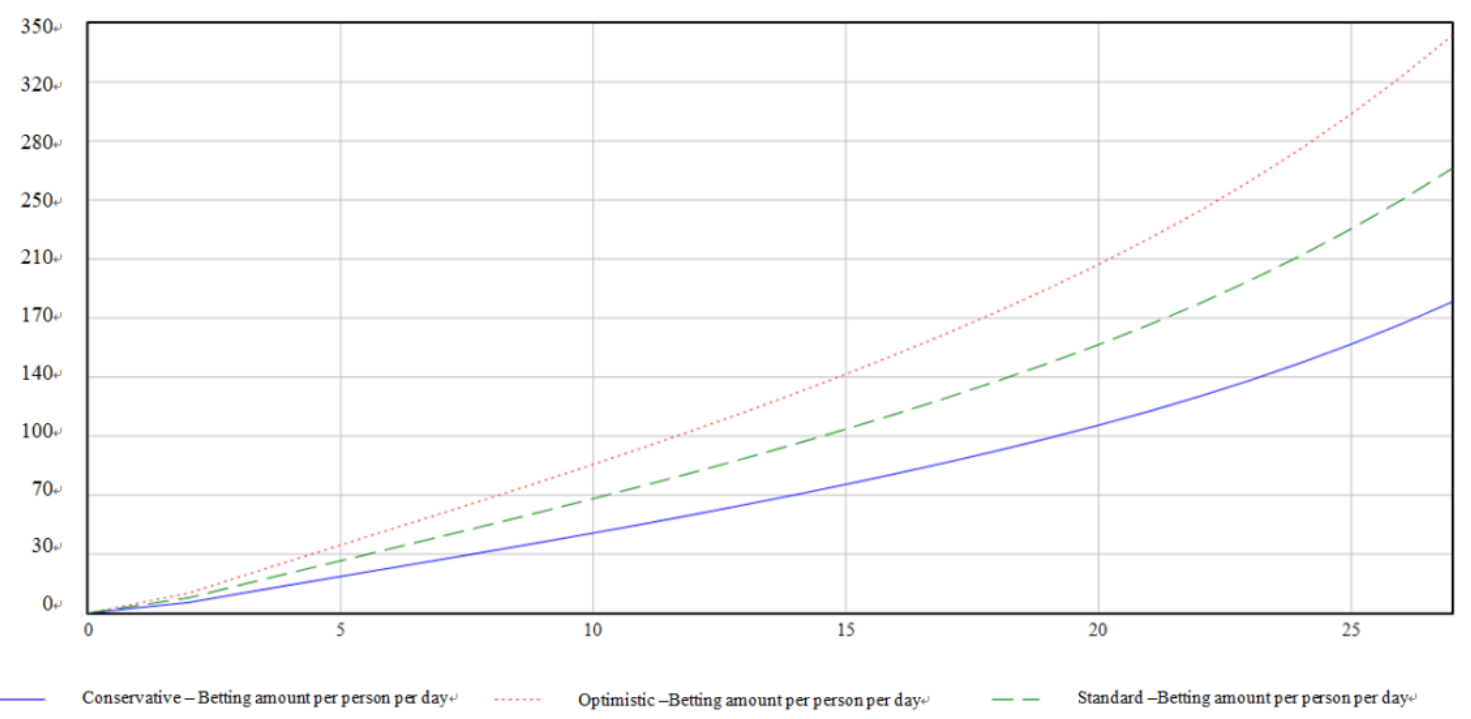

Figure 5: Regarding Simulation 3, the analysis of the simulated results of the change of betting rate of sports lottery per person per day daily sales amount (Unit: Million US\$ / Day); Note: The exchange rate is 28 New Taiwan dollars for 1 U.S. dollar.

As shown in Figure 5, the blue line represents the daily sales amount of sports lottery in the conservative situation. The green line represents the daily sales amount of sports lottery in the standard situation. The red line represents the daily sales amount of sports lottery in the optimistic situation. The change of betting amount per person per day will be changed and adjusted depending on the 
overall change of prosperity in the environment and individual income. The results of the simulated accumulated sales amount, overall speaking, it shows to be growing.

In the optimistic situation, up to the 9th day, the accumulated sales amount is about US\$ 0.08 billion. On the 18th day, it is about US\$ 0.18 billion. When it is accumulated to the 27 th day, it is about US\$ 0.35 billion. In the standard situation, up to the 9th day, the accumulated sales amount is about US\$ 0.06 billion. On the 18th day, it is about US\$ 0.14 billion. When it is accumulated to the 27 th day, conservative situation, it is about US $\$ 0.27$ billion. In the conservative situation, up to the 9th day, the accumulated sales amount is about US\$ 0.04 billion. On the 18th day, it is about US\$ 0.1 billion. When it is accumulated to the 27 th day, it is about US\$ 0.19 billion.

It indicates that with the same setting in increase and decrease rate (increase by $30 \%$ and decrease by $30 \%$ ), the betting amount per person per day will have greater impact in the accumulated sales amount of sports lottery.

By changing the "betting among per person per day" with standard situation as the criteria, in the optimistic situation, the accumulated sales amount increases about $9 \%$ when compared with the standard situation. With the standard situation as the criteria, in conservative situation, the accumulated sales amount decreases about $10 \%$ when compared with the standard situation.

\section{Simulation 4: Change of advertising expenditure during the FIFA World Cup}

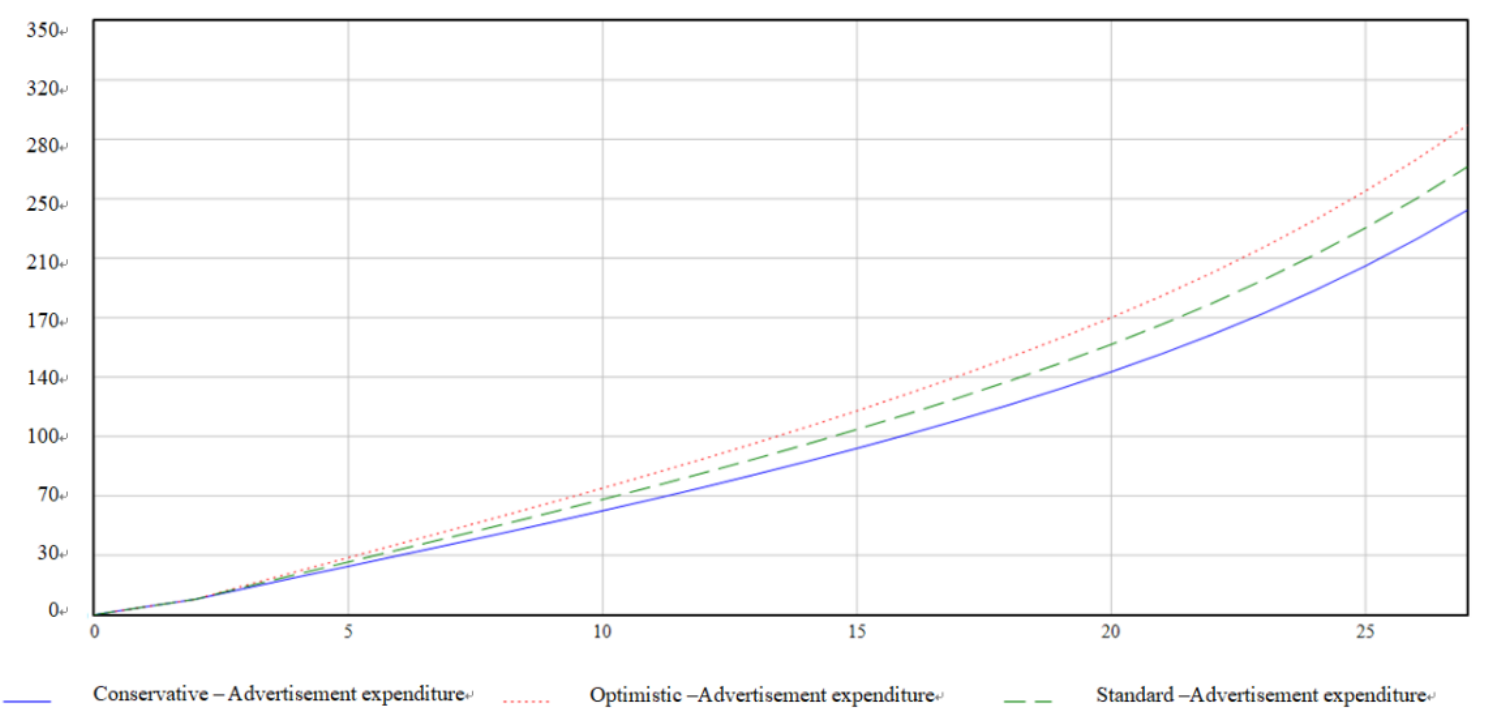

Figure 6: Regarding Simulation 4, the analysis of the simulated results of the accumulated sales amount per day of sports lottery (Unit: Million US\$ / Day); Note: The exchange rate is 28 New Taiwan dollars for 1 U.S. dollar.

As shown in Figure 6 the changing of advertising expenditure is the decision made by the sports lottery company. In the situations of optimistic, standard, and conservative, the simulated accumulated sales amount of sports lottery shows to be growing in trends. In the optimistic situation, up to the 9th day, the accumulated sales amount is about US\$ 0.06 billion. On the 18th day, it is about US \$ 0.15 billion. When it is accumulated to the 27 th day, it is about US $\$ 0.29$ billion. In the standard situation, up to the 9 th day, the accumulated sales amount is about US\$ 0.06 billion. On the 18th day, it is about US\$ 0.14 billion. When it is accumulated to the 27 th day, conservative situation, it is about US\$ 0.27 billion. In the conservative situation, up to the 9th day, the accumulated sales amount is about US\$ 0.05 billion. On the 18th day, it is about US\$ 0.13 billion. When it is accumulated to the 27 th day, it is about US\$ 0.24 billion.

By changing the "advertisement expenditure" with standard situation as the criteria, in the optimistic situation, the accumulated sales amount increases about $9 \%$ when compared with the standard situation. With the standard situation as the criteria, in conservative situation, the accumulated sales amount decreases about $10 \%$ when compared with the standard situation.

\section{Simulation 5: Change advertisement successful rate}




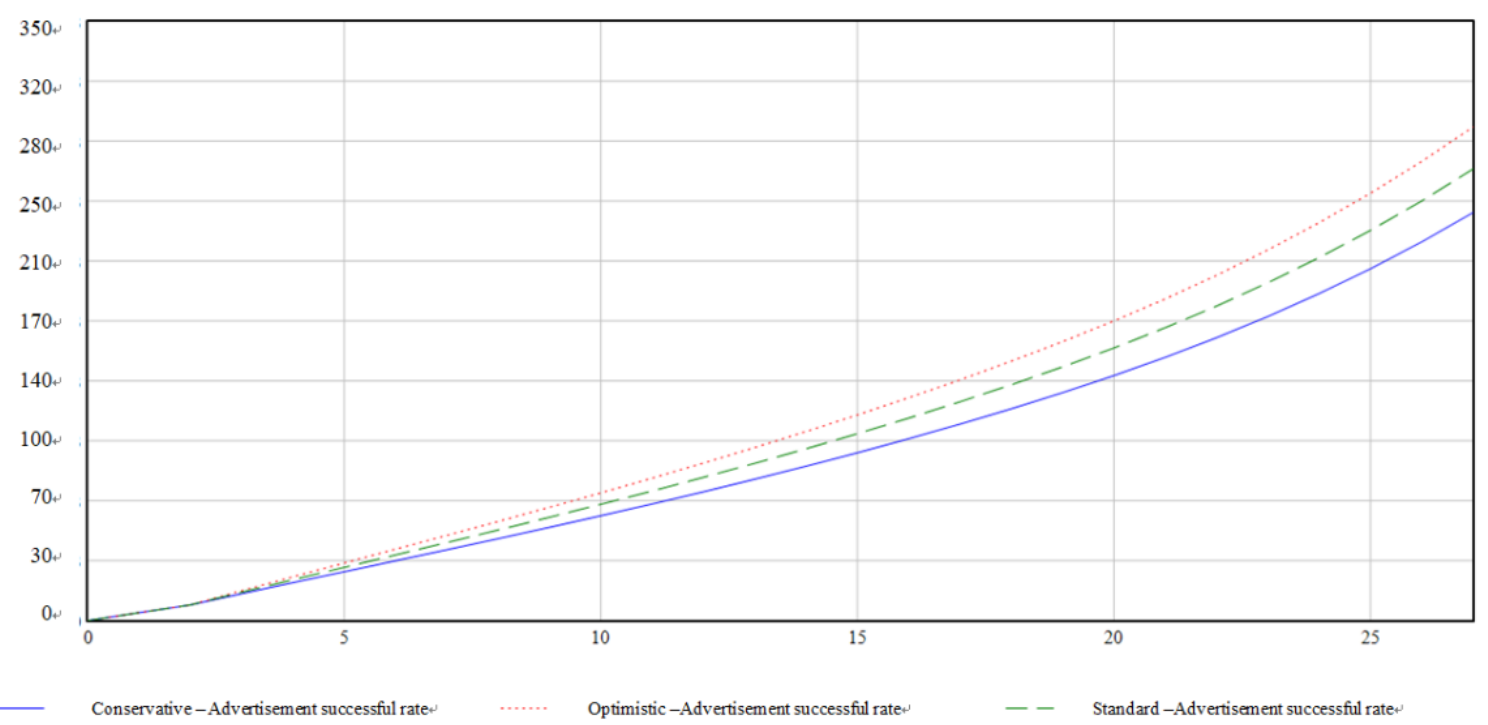

Figure 7: Regarding Simulation 5, the analysis of the simulated results of the accumulated sales amount per day of sports lottery (Unit: Million US\$ / Day); Note: The exchange rate is 28 New Taiwan dollars for 1 U.S. dollar.

As shown in Figure 7 regarding the impacts of the adjustment of advertising successful rate, in the situations of optimistic, standard, and conservative, the change in advertising successful rate is $0.013,0.001$, and 0.0007 . In the optimistic situation, up to the 9 th day, the accumulated sales amount is about US $\$ 0.06$ billion. On the 18th day, it is about US\$ 0.15 billion. When it is accumulated to the 27 th day, it is about US\$ 0.29 billion. In the standard situation, up to the 9th day, the accumulated sales amount is about US\$ 0.06 billion. On the 18th day, it is about US\$ 0.14 billion. When it is accumulated to the 27 th day, conservative situation, it is about US\$ 0.27 billion. In the conservative situation, up to the 9 th day, the accumulated sales amount is about US\$ 0.05 billion. On the 18 th day, it is about US\$ 0.13 billion. When it is accumulated to the 27 th day, it is about US\$ 0.24 billion.

By changing the "advertisement successful rate" with standard situation as the criteria, in the optimistic situation, the accumulated sales amount increases about $9 \%$ when compared with the standard situation. With the standard situation as the criteria, in conservative situation, the accumulated sales amount decreases about $10 \%$ when compared with the standard situation.

\section{Simulation 6: Change of the increase rate of potential bettors of sports lottery}

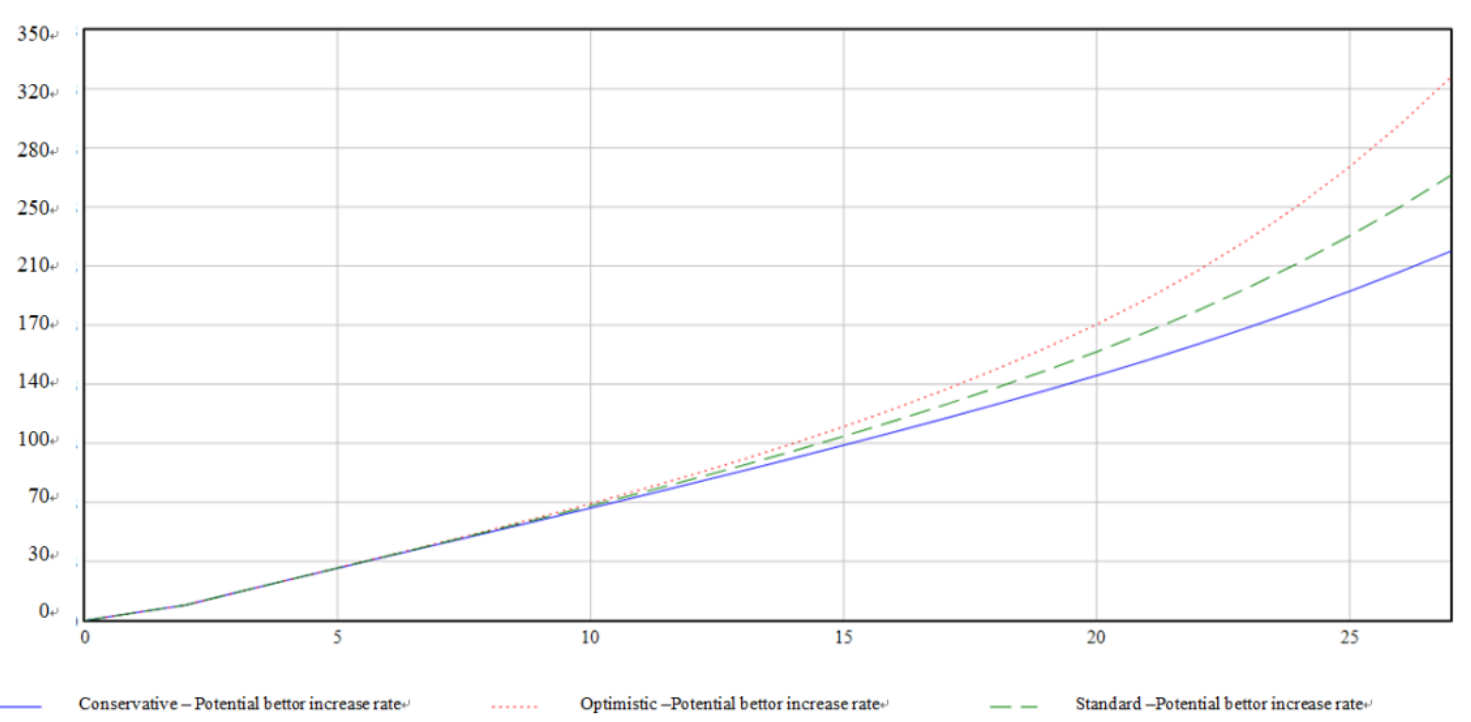

Figure 8: Regarding Simulation 6, the analysis of the simulated results of the accumulated sales amount per day of sports lottery (Unit: Million US\$ / Day); Note: The exchange rate is 28 New Taiwan dollars for 1 U.S. dollar.

In the optimistic situation, the red line in Figure 8 represents the accumulated sales amount per day of sports lottery. The blue line in Figure 8 represents the daily sales amount of sports lottery in the conservative situation. The green line in Fig. 8 represents the daily sales amount of sports lottery in the standard situation. 
As shown in Figure 8 the value of the changing of potential bettor increase rate is used to simulate the market conditions of the next FIFA World Cup. The accumulated sales amount of sports lottery is shown in Figure 8, presenting the trend of overall growth. In the optimistic situation, up to the 9th day, the accumulated sales amount is about US\$ 0.06 billion. On the 18 th day, it is about US\$ 0.15 billion. When it is accumulated to the 27 th day, it is about US\$ 0.33 billion. In the standard situation, up to the 9th day, the accumulated sales amount is about US\$ 0.06 billion. On the 18th day, it is about US\$ 0.14 billion. When it is accumulated to the 27 th day, conservative situation, it is about US\$ 0.27 billion. In the conservative situation, up to the 9th day, the accumulated sales amount is about US\$ 0.06 billion. On the 18th day, it is about US\$ 0.13 billion. When it is accumulated to the 27 th day, it is about US\$ 0.22 billion.

By changing the "potential bettor increase rate" with standard situation as the criteria, in the optimistic situation, the accumulated sales amount increases about $22 \%$ when compared with the standard situation. With the standard situation as the criteria, in conservative situation, the accumulated sales amount decreases about $17 \%$ when compared with the standard situation.

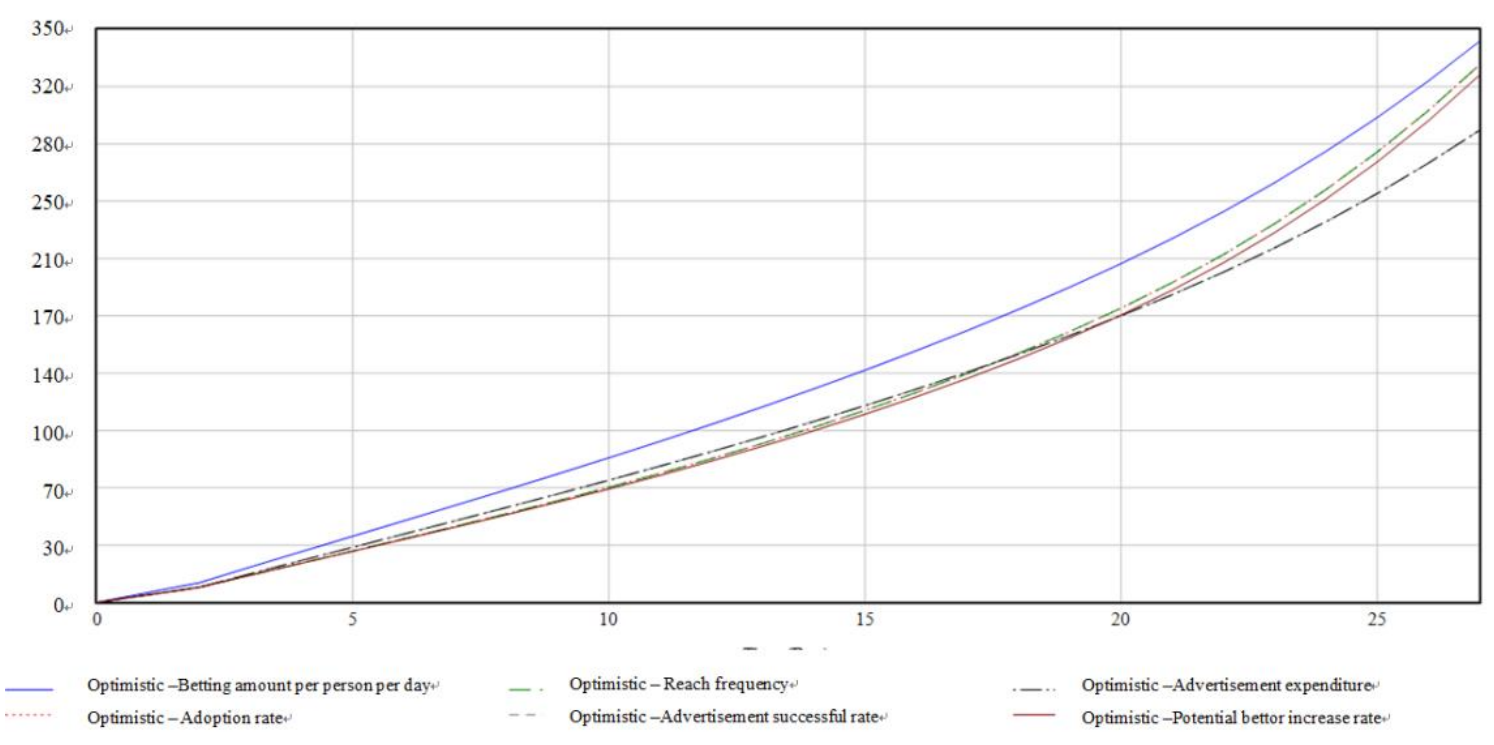

Figure 9: Regarding the above simulations, the accumulated sales amount of sports lottery per day in the optimistic situation. (Unit: Million US\$ / Day); Note: The exchange rate is 28 New Taiwan dollars for 1 U.S. dollar.

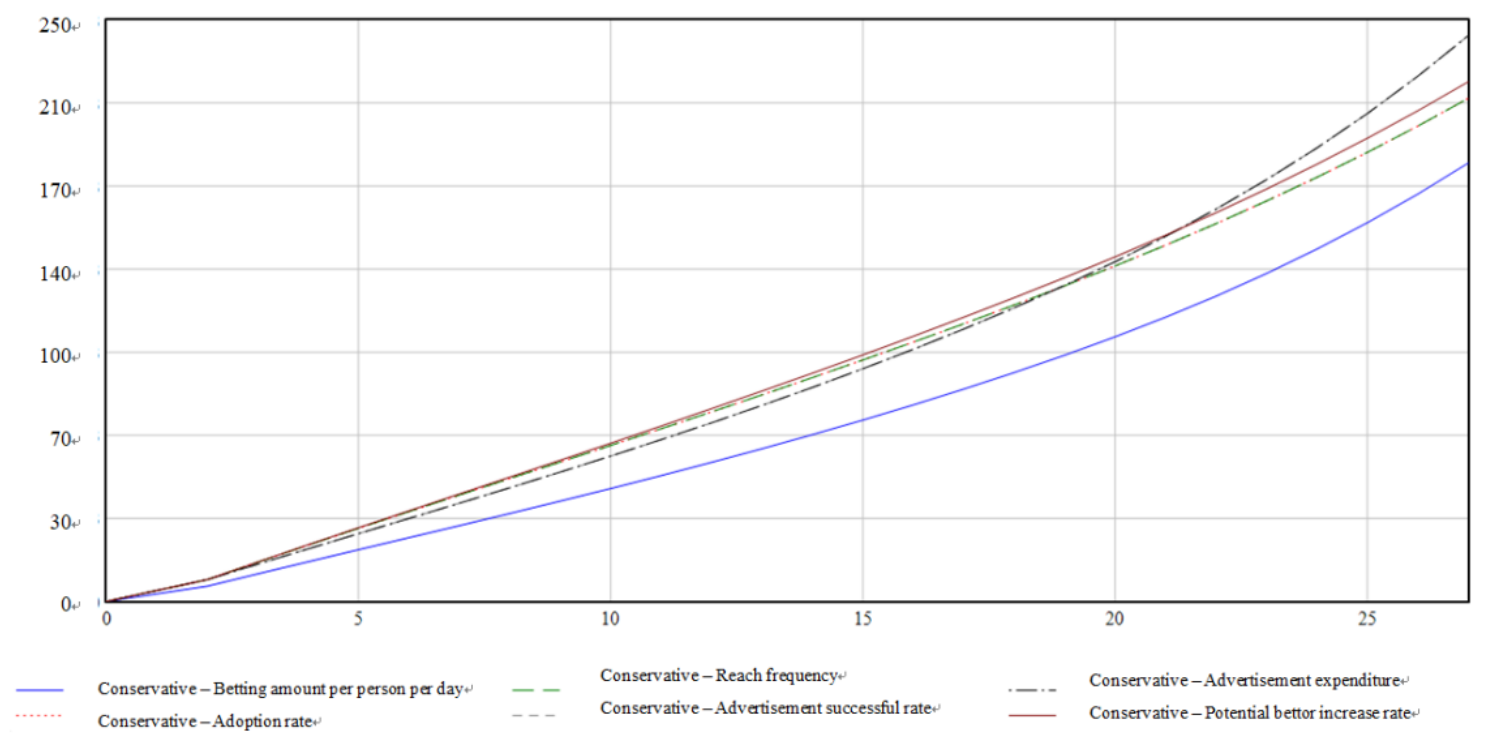

Figure 10: Regarding the above simulations, the accumulated sales amount of sports lottery per day in the conservative situation.

Unit: Million US\$ / Day

As shown in Figure 9 and Figure 10, in the financial effects of the abovementioned sales revenue system dynamics model of Taiwan Sports Lottery (Figure 1), the change of betting amount per person per day exerts the greatest impact on the daily sales amount. In the optimistic situation, it can reach the highest accumulated sales amount at about US\$ 0.35 billion. In the conservative situation, it shows the lowest accumulated sales amount at about US\$ 0.19 billion. 


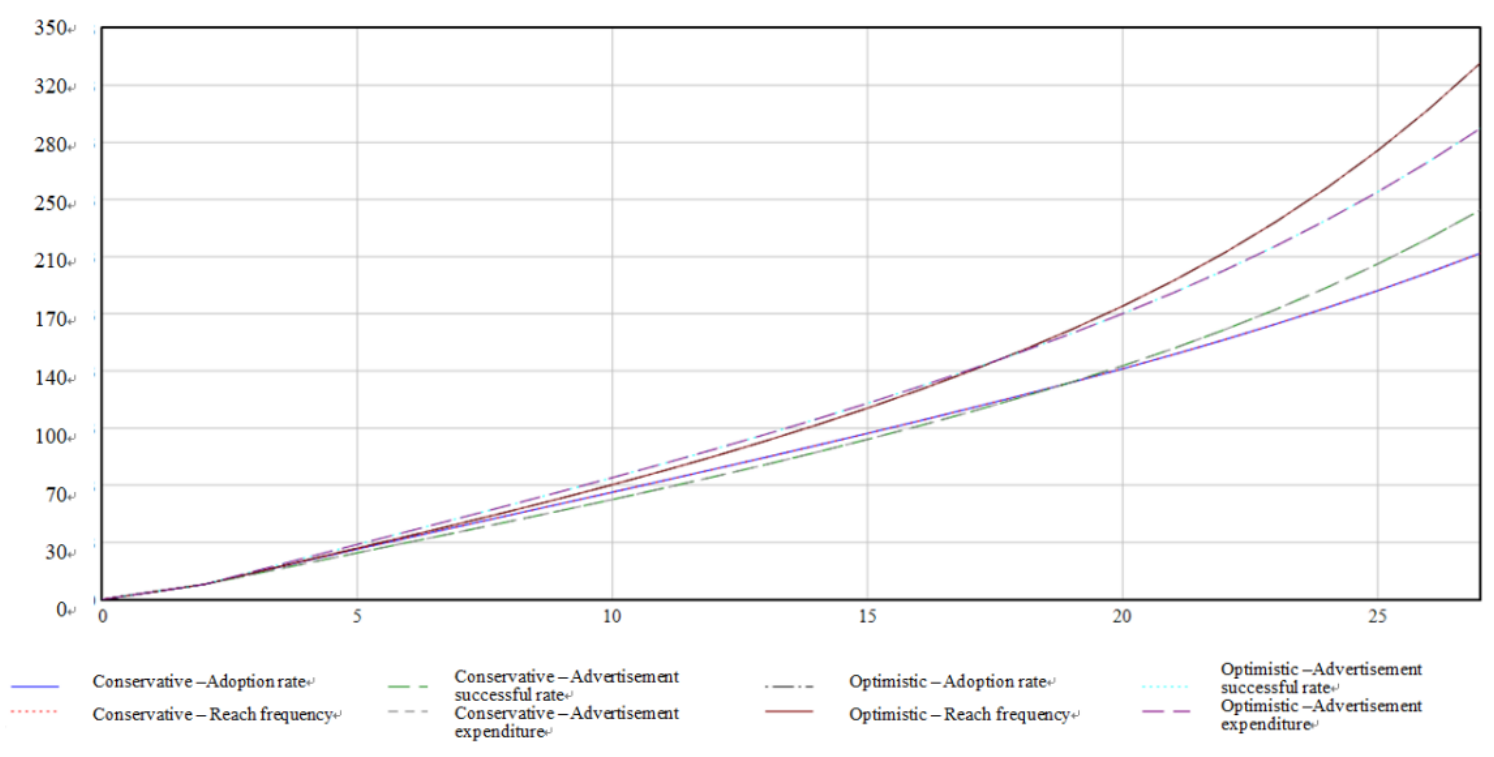

Figure 11: In the optimistic and conservative situations - Comparison of word-to-mouth and advertising effect Unit: Million US\$ / Day; Note: The exchange rate is 28 New Taiwan dollars for 1 U.S. dollar.

In the simulation setting table (Table 3), in the optimistic situation, the reach frequency is 13 and the adoption rate is 0.455 . It is observed Figure 11 that the lines of the change in reach frequency and adoption rate overlaps. It implies that the optimistic scales of both variables are the same. Therefore, it is known that in optimistic situation, the reach frequency and adoption rate contribute to the same in accumulation sales amount. The daily sales amount in the 27 th day is about US\$ 0.33 billion. In the conservative situation, the reach frequency is 7 and the adoption rate is 0.245 . It is observed Figure 11 that the lines of the change in reach frequency and adoption rate overlaps. As discussed above, it implies that the conservative scales of both variables are the same. The accumulated sales amount per day in the 27 th day is about US\$ 0.21 billion.

In the optimistic situation, the accumulated sales amount, observed before the 18th day, the effect of word-to-mouth is lower than advertisement. Observed after the 18th day, the effect of word-to-mouth is higher than advertisement. However, the result is opposite in the conservative situation. Observed before the 19th day, the effect of word-to-mouth is higher than advertisement. Observed after the 19th day, the effect of word-to-mouth is lower than advertisement. It suggests that advertisement yields better effects, compared with word-to-mouth. In a rather optimistic situation, the overall change of prosperity and environment, and individual's prediction of the future, as mentioned in Szymanski (2002), the word-to-mouth is more influential, or vice versa. Then, it is deduced that in the late-optimistic situation, it is able to reduce the advertisement expenditure and promote betting in sports lottery by word-to-mouth.

\section{Result and Discussion}

According to the findings of this research above, in different situations, the change of different simulations will bring different accumulated sales amount per day, constituting the fluctuation (increase or decrease) in quantity, as shown in Table 4.

Table 4: Quantity fluctuation (increase or decrease) in the simulated situations

\begin{tabular}{|c|}
\hline $\begin{array}{l}\text { Quantity fluctuation } \\
\text { (increase or decrease) }\end{array}$ \\
\hline
\end{tabular}

Simulation

\begin{tabular}{lll}
\hline Reach frequency & $24 \%$ & $-20 \%$ \\
\hline Adoption rate & $24 \%$ & $-20 \%$ \\
\hline Betting among per person per day & $30 \%$ & $-30 \%$ \\
\hline Advertisement expenditure & $9 \%$ & $-10 \%$ \\
\hline Advertisement successful rate & $9 \%$ & $-10 \%$ \\
\hline Potential bettors increase rate & $22 \%$ & $-17 \%$ \\
\hline
\end{tabular}

Source: Author

With the standard situation as the criteria, the difference between the standard situation and optimistic situation is $\mathrm{xx} \%$ increase. The difference between the standard situation and conservative situation is $\mathrm{xx} \%$ decrease. Table 4 explains the difference between the 
standard situation and optimistic situation. The biggest change in scale increase is the betting amount per person per day at $30 \%$. The difference between the standard situation and conservative situation, the biggest change in scale decrease is the betting amount per person per day at $-30 \%$. The difference between standard situation and optimistic situation, the second largest change in scale is the effects of word-to-mouth and reach frequency at $24 \%$. The least increase in the advertisement effects is the change in advertising expenditure and advertisement successful rate at $9 \%$. The difference between conservative situation and standard situation, the second largest change in scale is the reach frequency and adoption rate in word-to-mouth effects at $-20 \%$. The least increase in the advertisement effects is the change in advertising expenditure and advertisement successful rate at $-10 \%$.

By changing the betting amount per person per day, when comparing with the change in other simulations, can bring the biggest effect in both the scale of increase and decrease. It implies that if it is possible to promote the betting amount per person per day can boost the accumulated daily sales amount, exerting the most influential effects on the accumulated sales amount. In the optimistic situation, comparing the change in advertisement expenditure and advertising successful rate in advertising effect, the change in reach frequency and adoption rate in word-to-mouth bring higher accumulated sales amount, exceeding $15 \%$. In the conservative situation, the condition is the same. Changing the word-to-mouth parameter brings bigger effects in accumulated sales amount at $10 \%$, than changing advertisement effect parameter.

From the analysis of the simulation, it is known that, arranged from the effects of the increase in sales amount from the highest to the lowest: First, the change in betting amount per person per day brings the most significant effects. The second most changed effects are the reach frequency and adoption rate in the word-to-mouth effects. Changing these two simulations, the accumulated sales amount can reach as high as $24 \%$. According to the scale of the effects, the next one is the change of the potential bettor increase rate. It can bring the accumulated sales amount at $22 \%$ the highest. The least change is the change in advertisement expenditure and advertising successful rate in advertising effect. The accumulated sales amount may increase $9 \%$. Bettors will be influenced by the advertisement effects(Hing et al., 2019). According to the analysis above, the policy implications as followings:

\section{Change of word-to-mouth effect (reach frequency or adoption rate)}

The growth in the participation rate and purchase rate of sports lottery can promote onsite betting, TV broadcasting, and new media, such as the internet, mobile phone, and social media (Hing et al., 2014). It is able to use social media to share the information of sports lottery and invite friends to click like in order to expand contact rate among people. It will promote the contact rate. The popularization of the internet and the drive in the growth of sports lottery (Capital, 2013). The mobile phone allows bettors to get in contact with betting websites. They can bet anywhere regardless of the time and location. The merit of betting online is that it is more convenient. Up to now, according to the data of the internet use survey conducted by Taiwan Network Information Center, with the popularization of mobile network in Taiwan, the using rate increases every year. It makes betting more convenient, enhancing online betting. Promoting online betting, it can promote the potential bettor increase rate. According to the data of Taiwan Sports Lottery from May 1, 2018 to April 30, 2019, the betting rate with mobile phone and tablet computer was as high as 70\%. Overall speaking, the promotion of betting demand can further promote the accumulated sales of Taiwan Sports Lottery.

\section{Change of betting amount per person per day}

By comparing with the standard situation, in the optimistic situation, the simulation of the increase of betting amount per person per day shows to have the most significant effects. Changing the betting amount per person per day can increase $30 \%$ of the accumulated sales amount. TV broadcasting is helpful to the betting increase rate and betting amount per person per day. If more matches are broadcasted live, there will be more people to bet. Providing live-bet during the live broadcasting of TV, the means of providing live broadcast and live-bet, the effects will be optimal. Live-bet is the best way to promote sales. TV live broadcasting is the most helpful. It is necessary to provide TV live broadcasting during live-bet. Otherwise, people can only watch their mobile phone during live-bet. It will affect the accumulated sales amount.

\section{Change advertisement effect (advertisement expenditure and advertisement successful rate)}

Advertisement can promote the sales of sports lottery (Weibe, 2008). Advertisements are brought through TV, websites, celebrities, etc. to promote sports lottery (Compliance, 2013). Through advertisements, prizes can attract more bettors. When the more the people watching the advertisement, the better the advertisement effects. Advertisements should be shown during high viewership ratings to reap the best advertisement effects. Comparatively speaking, the advertisement expenditure during these times will be the highest. Therefore, it is better to find bigger company to pay the comparatively high advertisement expenditure.

\section{Change the potential bettor increase rate}

Now, Taiwan Sports Lottery has launched a website to increase potential bettors - Sports Lottery Training Camp to allow people trying to bet sports lottery online. It allows them to get familiar with sports lottery types and ways of betting operated by Taiwan Sports Lottery to arouse their interest in sports lottery betting. It also allows retailers, sales representatives and agents try betting online so that recruits in betting centers to get familiar with the sports lottery betting in the Taiwan Sports Lottery Training Camp.Increase the number of potential bettors, it encourages more people interest in sports in bet in sports lottery. 


\section{In different situations, different effects should be emphasized}

According to the observation report in Figure 11, in the optimistic situation, in the early stage, it should emphasize on advertisement effects. In the latter stage, it should pay more attention to word-to-mouth effects. In the conservative situation, in the early stage, it should emphasize on word-to-mouth effects. In the latter stage, it should pay more attention to advertisement effects. It will be more helpful to the operation of sports lottery. Therefore, Taiwan Sports Lottery is suggested to maintain an optimistic view towards future growth with judgment when huge matches to be held in the future. That is, emphasize on advertisement in the beginning; after more people get in touch with sports lottery, the effects will be better by the word-to-mouth effect.

\section{With limited resources, it should pay more attention to promote higher sales amount with priority}

In the condition of obtaining limited resources, if it is only possible to increase the betting amount per person per day, it is better to use the resources in this part. When obtaining limited resources, if it is possible to change betting amount per person per day and change the word-to-mouth effects, it should use the resources on changing betting amount per person per day, contact rate, and adoption rate first. It is also possible to change betting amount per person per day, reach frequency, adoption rate through the methods abovementioned.

\section{Conclusions}

In the past, there were very few studies on the sales of sports lottery with system dynamics and innovation diffusion theory. This research regards FIFA World Cup 2018 as the object of study, using the integration of system dynamics and innovation diffusion model as the foundation to construct a dynamic model for the analysis the impacts of advertisement effects and word-to-mouth effects on the financial effects. It is suggested that Taiwan Sports Lottery can apply the findings to promote betting amount per person per day to promote its products and services. In addition, this research would like to advise consumers to suggest Taiwan Sports Lottery, regarding word-to-mouth effects, to construct social media accounts specially for betting purposes. It will communicate sports lottery information promptly and effectively. It can also avoid illegal sales of sports lottery. Finally, in the future, it should change the parameter of the Taiwan Sports Lottery system dynamics model constructed in this research. With the coming of the network era, it is possible to add parameters of network-related. This model can be applied in FIFA World Cup and other major matches held in the future.

\section{References}

Bass, F. M. 1969. A new product growth for model consumer durables. Management science, 15, 215-227.

Blackman Jr, A. W. 1974. The market dynamics of technological substitutions. Technological Forecasting and Social Change, 6 , 41-63.

Capital, H. G. 2013. There's nothing virtual about the opportunity in real-money gambling. H2 Gambling Capital \& Odobo Gibraltar. Compliance, G. 2013. Gambling advertising and sport: A comparison of regulated markets. Sydney: Australian Wagering Council. Retrieved from ....

Cornelissen, S. 2010. Football's tsars: proprietorship, corporatism and politics in the 2010 FIFA World Cup. Soccer \& Society, 11, 131-143.

Denzin, N. 1970. Strategies of multiple triangulation. The research act in sociology: A theoretical introduction to sociological method, 297, 313.

Denzin, N. K. 2017. The research act: A theoretical introduction to sociological methods, Transaction publishers.

Forrester, J. W. 2007. System dynamics—-the next fifty years. System Dynamics Review: The Journal of the System Dynamics Society, 23, 359-370.

Herskowitz, S. 2016. Gambling, saving, and lumpy expenditures: Sports betting in Uganda. University of California, Berkeley.

Hing, N., Cherney, L., Blaszczynski, A., Gainsbury, S. M. \& Lubman, D. I. 2014. Do advertising and promotions for online gambling increase gambling consumption? An exploratory study. International Gambling Studies, 14, 394-409.

Hing, N., Russell, A. M., Thomas, A. \& Jenkinson, R. 2019. Wagering advertisements and inducements: Exposure and perceived influence on betting behaviour. Journal of gambling studies, 35, 793-811.

Jenkinson, R., De Lacy-Vawdon, C. \& Carroll, M. L. 2019. Weighing up the odds: Sports betting and young men, Australian Gambling Research Centre, Australian Institute of Family Studies.

Kaplanski, G. \& Levy, H. 2010. Exploitable predictable irrationality: The FIFA World Cup effect on the US stock market. Journal of Financial and Quantitative Analysis, 535-553.

La Fleur, B. 2019. La Fleur's World Lottery Almanac. Boyds: TLF Publications, Inc.

Lee, C.-K. \& Taylor, T. 2005. Critical reflections on the economic impact assessment of a mega-event: the case of 2002 FIFA World Cup. Tourism management, 26, 595-603.

Lewis, C. D. 1982. Industrial and business forecasting methods: A practical guide to exponential smoothing and curve fitting, Butterworth-Heinemann.

Mahajan, V. 2010. Innovation diffusion. Wiley International Encyclopedia of Marketing.

Mahajan, V., Muller, E. \& Wind, Y. 2000. New-product diffusion models, Springer Science \& Business Media. 
Mahajan, V. \& Peterson, R. A. 1979. First-purchase diffusion models of new-product acceptance. Technological Forecasting and Social Change, 15, 127-146.

Mbore, C. K., Sang, J. \& Komen, J. 2019. Management control system, organizational processes and institutional performance of technical training institutions in Kenya. International Journal of Research in Business and Social Science (2147-4478), 8, 229-239.

Milling, P. M. 1996. Modeling innovation processes for decision support and management simulation. System Dynamics Review: The Journal of the System Dynamics Society, 12, 211-234.

Mwadime, A. 2017. Implications of Sports Betting In Kenya: Impact of Robust Growth of the Sports Betting Industry. United States International University-Africa.

Paich, M. \& Sterman, J. D. 1993. Boom, bust, and failures to learn in experimental markets. Management science, 39, $1439-1458$.

Prahalad, C. K. \& Ramaswamy, V. 2000. Co-opting customer competence. Harvard business review, 78, 79-90.

Robinson, B. \& Lakhani, C. 1975. Dynamic price models for new-product planning. Management science, 21, $1113-1122$.

Rogers, E. M. 1961. Bibliography on the Diffusion of Innovations.

Rogers, E. M. 1963. What are innovators like? Theory into Practice, 2, 252-256.

Rogers, E. M. 2010. Diffusion of innovations, Simon and Schuster.

Rogers, E. M. \& Williams, D. 1983. Diffusion of. Innovations (Glencoe, IL: The Free Press, 1962).

Senge, P. M. \& Forrester, J. W. 1980. Tests for building confidence in system dynamics models. System dynamics, TIMS studies in management sciences, 14, 209-228.

Sharif, M. N. \& Ramanathan, K. 1984. Temporal models of innovation diffusion. IEEE Transactions on Engineering Management, 76-86.

Sterman, J. 2000. Instructor's Manual to Accompany Business Dyanmics: Systems Thinking and Modeling for a Complex World, McGraw-Hill.

Sterman, J. D. 1994. Learning in and about complex systems. System dynamics review, 10, 291-330.

Szymanski, S. 2002. The economic impact of the World Cup. World Economics, 3, 169-177.

Uzochukwu, C. 2021. An Assessment of Pattern, Motivation and Effects of Online Sports Betting Among Youths in South-East Nigeria. International Journal of Innovative Science and Research Technology, 6.

Weibe, J. 2008. Internet gambling: Strategies to recruit and retain customers. Guelph: Ontario Problem Gambling Research Centre.

Yelkur, R., Tomkovick, C. \& Traczyk, P. 2004. Super Bowl advertising effectiveness: Hollywood finds the games golden. Journal of Advertising Research, 44, 143-159.

Yeon, S.-J., Park, S.-H. \& Kim, S.-W. 2006. A dynamic diffusion model for managing customer's expectation and satisfaction. Technological Forecasting and social change, 73, 648-665.

Publisher's Note: SSBFNET stays neutral with regard to jurisdictional claims in published maps and institutional affiliations.

\section{(a) (1)}

(C) 2021 by the authors. Licensee SSBFNET, Istanbul, Turkey. This article is an open access article distributed under the terms and conditions of the Creative Commons Attribution (CC BY) license (http://creativecommons.org/licenses/by/4.0/).

International Journal of Research in Business and Social Science (2147-4478) by SSBFNET is licensed under a Creative Commons Attribution 4.0 International License. 